\title{
Studies on the Coagulation of Chicken Blood
}

\author{
VI. Use of Cobalt Carbonate, Barium Phosphate, Lead Carbonate and \\ Lead Phosphate for Differentiation and Assay of Strontium Carbonate \\ Non-adsorbable Labile Factors
}

$\emptyset Y V I N D S \emptyset R B Y E *$ and INGER KRUSE

Department of Biochemistry and Nutrition, Polytechnic Institute, Copenhagen, Denmark

\begin{abstract}
The multiple nature of the labile factor activity of strontium carbonate adsorbed oxalated chicken plasma was revealed by adsorption studies. The results obtained with fifty-two selected crystalline adsorbents are explained as adsorption of four different labile coagulation factors by four different groups of adsorbents, represented by the title compounds. Provisional names for these factors are suggested: $\lambda$ (lambda)-factor is selectively adsorbed by cobalt carbonate, $\pi$ (pi)factor by lead carbonate, $\beta$ (beta)-factor by lead phosphate, and $\gamma$ (gamma)-factor by barium phosphate. The activity of $\lambda$-factor is independent of the concentrations of the other three factors. The activities of $\beta$ - and $\pi$-factors are also mutually independent, whereas $\gamma$ factor acts as a synergist both for $\pi$-factor and for $\beta$-factor. When Russell's viper venom (RVV), with or without cephalin, is substituted for thromboplastin in the assay system, $\gamma$-and $\pi$-factors are inactive. $\beta$-Factor is active only if $R V V$ is supplemented with cephalin. $\lambda$ Factor is part of the labile factor activity measured by all three assay accelerators. Determination of the minimum amount of the adsorbents required for maximal adsorption of labile factor activity is suggested as a possibility for quantitative determination of the adsorbable factors.
\end{abstract}

$\mathbf{I}^{\mathrm{t}}$ was shown in a previous paper ${ }^{1}$ that the reduced labile factor activity of strontium (or barium) carbonate adsorbed oxalated chicken plasma was due to adsorption of two labile coagulation factors. The two factors could be adsorbed separately by other adsorbents: $\psi$-factor by calcium carbonate, calcium oxalate or calcium molybdate and $\sigma$-factor by barium oxalate, barium chromate or strontium oxalate.

A number of other insoluble inorganic compounds have been tested for adsorption of the strontium carbonate non-adsorbable labile factor activity.

* Fellow of the Royal Norwegian Council for Scientific and Industrial Research.

Acta Chem. Scand. 16 (1962) No. 6 
In most cases only a part of the total activity could be adsorbed by each of these adsorbents. These results indicated that the labile factor activity of strontium carbonate adsorbed oxalated chicken plasma is of a complex nature and may be regarded as the combined activities of a number of separate labile coagulation factors differing characteristically in adsorbability. Our previous experiences with compounds showing partial adsorption of the strontium carbonate non-adsorbable labile factor activity, were presented in a short communication ${ }^{2}$. The present study deals with fifty-two selected adsorbents by means of which four different strontium carbonate non-adsorbable labile coagulation factors can be adsorbed separately.

\section{MATERIALS AND METHODS}

In addition to methods and materials described previously ${ }^{1,3}$ the following materials were used in the present study.

Strontium carbonate plasma. Oxalated chicken plasma was adsorbed by strontium carbonate $\left(20-25 \mathrm{mg} / \mathrm{ml}\right.$ of a commercial preparation $\left.{ }^{*}\right)$ to remove the $x_{-}, \delta-, \varphi-, \psi$ - and $\sigma$-factors completely.

Adsorbents. The compounds listed below were used as plasma adsorbents in the present study.

Carbonates of $\mathrm{Co}$ and $\mathrm{Pb}$, oxides of $\mathrm{W}, \mathrm{Sb}$ and $\mathrm{Bi}, \mathrm{Sn}$ mono- and dioxide, sulfates of $\mathrm{Pb}$ and $\mathrm{Ba}$, ferri-ferrocyanide, $\mathrm{Pb}$-metaborate, and phosphates of $\mathrm{Ba}, \mathrm{Sr}, \mathrm{Mg}$, and $\mathrm{Co}-$ all were kindly supplied by the Department of Inorganic Chemistry of The Polytechnic Institute. Other adsorbents were prepared in this laboratory, according to procedures described in Gmelin-Kraut's Handbuch der Anorganischen Chemie. These adsorbents were prepared from high purity chemicals by (1) precipitation of aqueous solutions, (2) thermal decomposition of unstable compounds, or (3) reactions between solids in the molten state.

Oxalates of $\mathrm{Co}$ and $\mathrm{Pb}$ were prepared from hot $\left(90^{\circ} \mathrm{C}\right)$ aqueous solutions of soluble salts by precipitation with excess of a hot solution of ammonium oxalate and oxalic acid in equimolar amounts.

Fluorides of $\mathrm{Mg}$ and $\mathrm{Sr}$ were prepared by melting a mixture containing 5 parts of magnesium chloride or 6 parts of strontium chloride mixed with 4 parts of sodium fluoride and 4 parts of sodium chloride.

Borates of Co and Mn were prepared from the oxide and the carbonate, respectively, by melting with an equimolar mixture of potassium bifluoride and boric acid anhydride.

Oxides of $\mathrm{Co}, \mathrm{Ni}$ and $\mathrm{Cd}$ were prepared by thermal decomposition of the carbonates or oxalates at $500-700^{\circ} \mathrm{C}$ in air. A commercial preparation of Be-oxide was made crystalline by heating with boric acid anhydride at $1200^{\circ} \mathrm{C}$.

Sulfite of Ca was prepared by $\mathrm{SO}_{2}$-gas saturation of an aqueous suspension of calcium carbonate, followed by filtration and heating of the filtrate on a steam bath.

Sulfides of $\mathrm{As}$ and $\mathrm{Sb}$ were prepared from dilute hydrochloric acid solutions of the oxides by precipitation with hydrogen sulfide gas or sodium thiosulfate solution. After washing and drying the products were heated in sealed ampullae at $200^{\circ} \mathrm{C}$ for at least $48 \mathrm{~h}$.

Phosphates of $\mathrm{Be}, \mathrm{Zr}, \mathrm{Th}, \mathrm{Fe}, \mathrm{Ce}$ and $\mathrm{Al} * *$ were prepared from the oxides $(\mathrm{Be}, \mathrm{Zr}$ ), oxalate $(\mathrm{Th})$, carbonate $(\mathrm{Fe})$ and sulfates $(\mathrm{Ce}, \mathrm{Al})$, respectively, by melting with 5 parts of sodium metaphosphate at $1000^{\circ} \mathrm{C}$.

The phosphate of Mn was prepared by heating of a $10 \%$ phosphoric acid solution saturated with manganese carbonate. The phosphate of $\mathrm{Pb}$ was prepared from a lead acetate solution by precipitation with sec. sodium phosphate. A crystalline product was obtained by heating of the washed amorphous precipitate suspended in $8-10 \%$ acetic acid, to $90-100^{\circ} \mathrm{C}$.

* From H. Struers chemiske Laboratorium, Copenhagen.

** Whether ortho- or meta-phosphates were formed by this procedure was not investigated.

Acta Chem. Scand. 16 (1962) No. 6 
Basic lead chromate was prepared from a suspension of yellow lead chromate in slightly more than equimolar amounts of sodium hydroxide (as a $5 \%(\mathrm{w} / \mathrm{v})$ solution). The suspension was boiled until the colour had changed to bright brick red.

Silicates of $\mathrm{Be}, \mathrm{Mn}$ and Co were prepared from the sulfates (Be, Mn) and the oxide (Co), respectively, by melting with sodium metasilicate and sodium sulfate or boric acid anhydride.

Aluminates of Co and Be were prepared by melting sodium chloride (sulfate) and sodium aluminate with metal chloride (sulfate) in excess. After washing and drying the insoluble product was remelted with 5 parts of boric acid anhydride.

Tungstates of $\mathrm{Ca}, \mathrm{Ba}, \mathrm{Mn}, \mathrm{Fe}, \mathrm{Pb}$, and Co were prepared by melting one part of sodium tungstate with two parts of sodium chloride (sulfate) and a $2-3$ fold excess of metal chloride (sulfate). Tungstate of Ce was prepared similarly from cerous sulfate with sodium tungstate in excess.

Molybdates of $\mathrm{Ba}, \mathrm{Pb}$, and Co were prepared by melting one part of sodium molybdate with two parts of sodium chloride and a $2-3$ fold excess of metal chloride.

All preparations were thoroughly washed with distilled water, treated with $96 \%$ ethanol and dried at $80^{\circ} \mathrm{C}$ overnight before use. The melts were treated with water to remove soluble material and pulverized before the final washing. The adsorbents were obtained as crystalline or micro-crystalline powders. For comparison, amorphous modifications of a few of the adsorbents were also prepared.

\section{EXPERIMENTS AND RESULTS}

Adsorption of strontium carbonate non-adsorbable labile factors. Inorganic insoluble compounds were tested for adsorption of the strontium carbonate non-adsorbable labile factor activity as described previously ${ }^{1}$, using strontium carbonate preadsorbed oxalated chicken plasma instead of untreated plasma. The amounts of strontium carbonate used for preadsorption were more than adequate for complete adsorption of the $\varkappa^{-}, \delta$-, $\varphi^{-}, \psi^{-}$, and $\sigma$-factors. No inhibitory effects could be detected in plasmas treated with these adsorbents, and plasma $\mathrm{pH}$ was not changed significantly ${ }^{1}$.

The results of a preliminary testing of the compounds described in this paper, are summarized in Table 1. The adsorbents listed caused only partial adsorption of the labile factor activity of strontium carbonate plasmas and could thus be classified as selective adsorbents ${ }^{1}$.

A detailed study of the effect of the adsorbents revealed that labile factor activity was adsorbed proportionally to the amounts of adsorbent added until, at a certain concentration of adsorbent, no more labile factor activity could be adsorbed by increasing the amounts of adsorbent. Renewed treatment with the same adsorbent caused no further reduction of the labile factor activity. Typical adsorption curves obtained with 8 different adsorbents are shown in Figs. $1(\mathrm{~A}-\mathrm{H})$. All the other adsorbents of Table 1 gave similar adsorption curves.

As pointed out previously ${ }^{1}$, partial adsorbability of the labile factor activity by an adsorbent indicates that the adsorbable and the non-adsorbable activities are not due to the same labile coagulation factors. The labile factor activity of strontium carbonate preadsorbed plasmas may be regarded, therefore, as the combined activity of distinct labile coagulation factors with characteristic differences in adsorbability.

Matching experiments. The effects of different adsorbents were compared in a series of matching experiments, carried out as described previously ${ }^{1}$ 


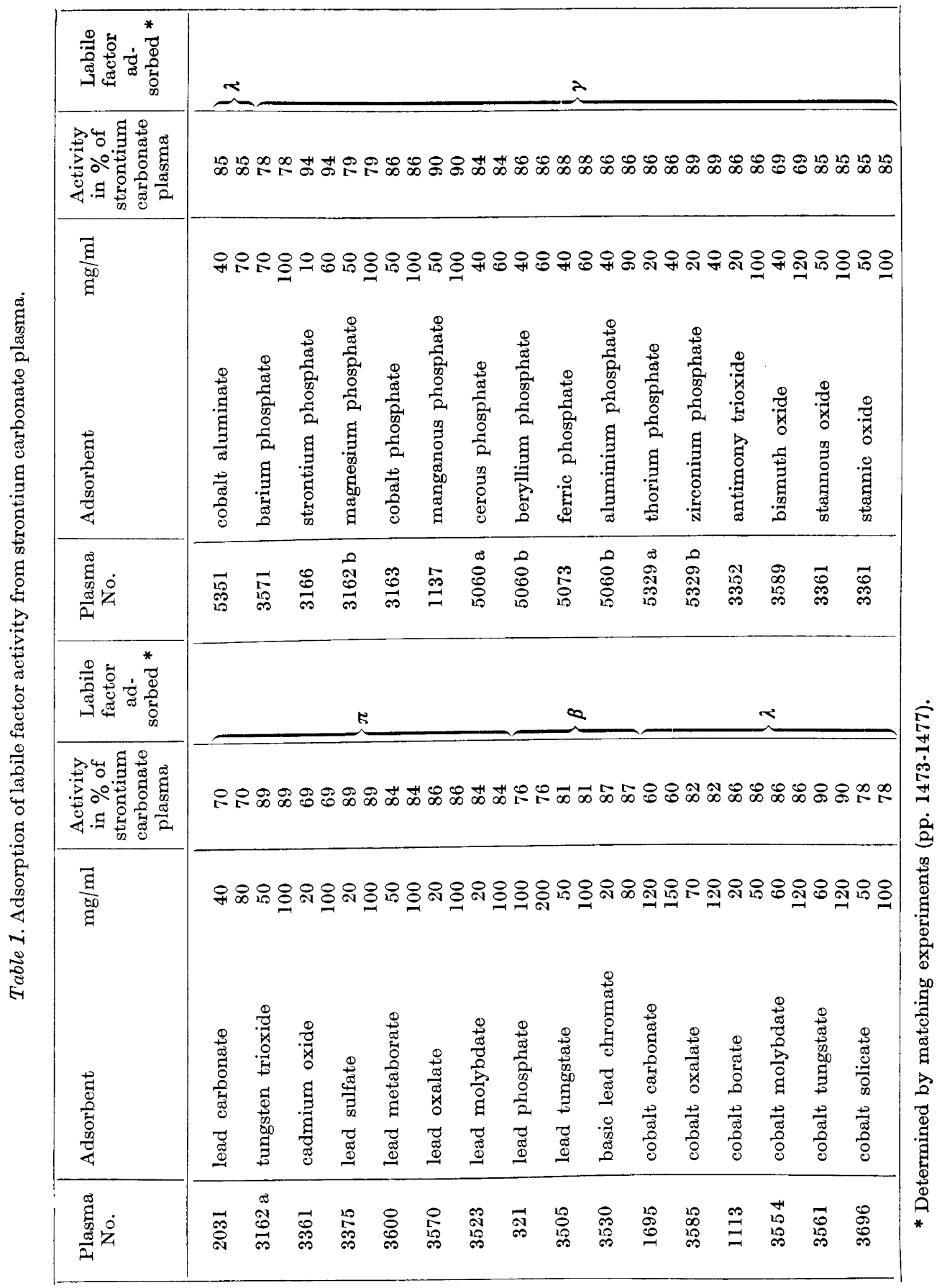

Acta Chem. Scand. 16 (1962) No. 6 


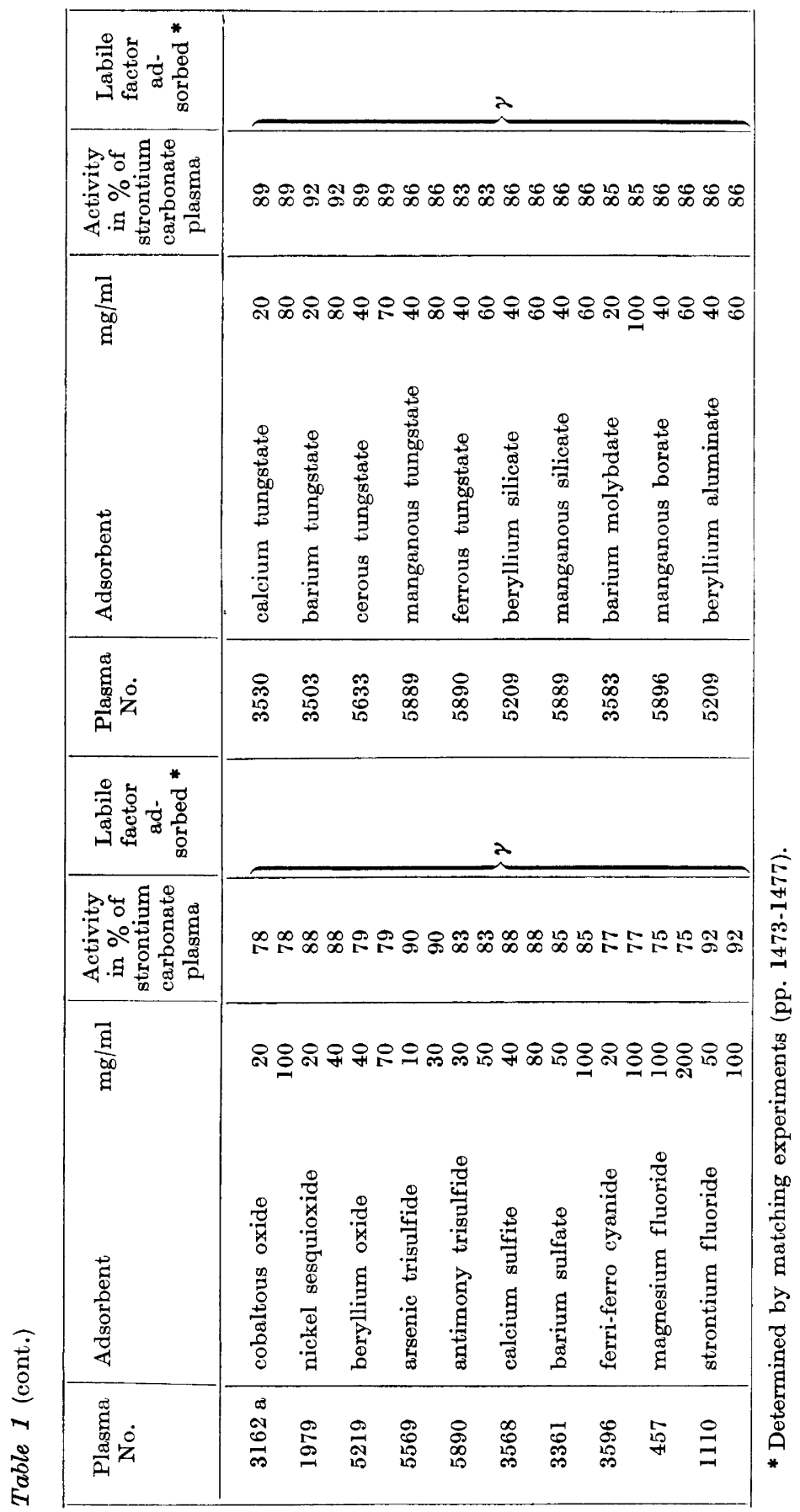

Acta Chem. Scand. 16 (1962) No. 6 

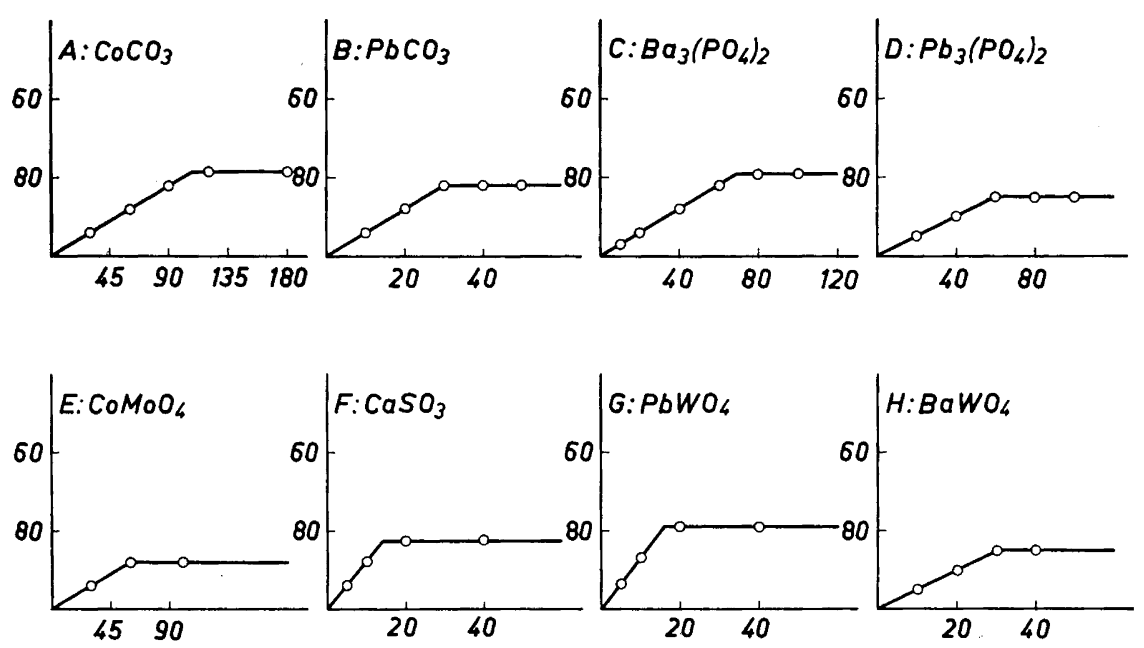

Figs. 1. Adsorption of labile factor activity.

Ordinates: labile factor activity in \% of strontium carbonate plasma. Abscissæ: adsorbent in $\mathrm{mg} / \mathrm{ml}$.
A: cobalt carbonate;
B: lead carbonate;
C: barium phosphate;
D: lead phosphate;

E: cobalt molybdate;

F: calcium sulfite;

G: lead tungstate;

$\mathrm{H}$ : barium tungstate.

with strontium carbonate plasma instead of untreated plasma. Representative results of such experiments are shown in Figs. 2-4 (A-H). The effects obtained by use of cobalt carbonate, barium phosphate, lead carbonate and lead phosphate were first compared.

The labile factor activities adsorbed by cobalt carbonate and barium phosphate were not reduced after preadsorption of strontium carbonate plasmas by barium phosphate and cobalt carbonate, respectively (Figs. $2 \mathrm{~A}$ and $2 \mathrm{~B}$ ), and the minimum amounts of each of the two adsorbents required for maximal adsorption of activity remained unchanged after preadsorption by the other adsorbent. The labile factor activities adsorbed by these adsorbents are therefore due to two different labile coagulation factors, and the activities of the factors are mutually independent. Parallel adsorption curves are thus the results of matching experiments with compounds adsorbing different factors with additive effects.

Experiments with lead carbonate and barium phosphate gave the two sets of curves shown in Figs. 2C and 2D. The minimum amounts of each of these adsorbents necessary for maximal adsorption of activity, were not changed after preadsorption by the other adsorbent, but the adsorbable activities were reduced. The experiments indicate that the activities adsorbed by lead carbonate and barium phosphate are due to two different labile factors, the activity of each of which is increased in the presence of the other. Converging 

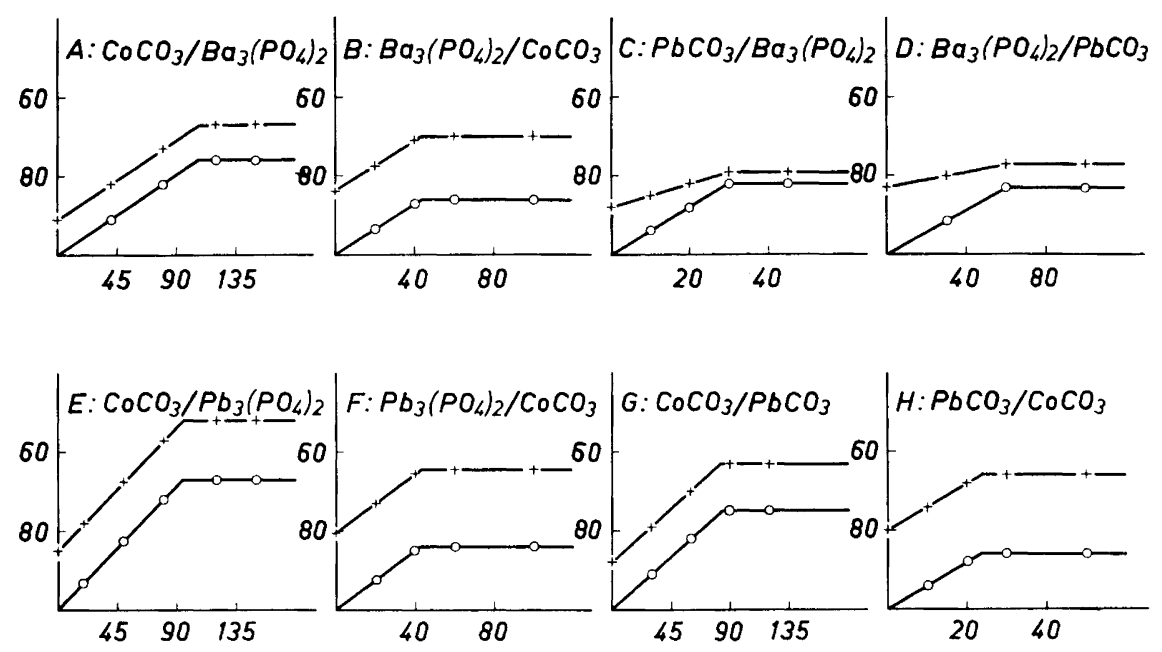

Figs. 2. Comparison of adsorbents I.

Ordinates: labile factor activity in $\%$ of strontium carbonate plasma.

Abscissæ: adsorbent in $\mathrm{mg} / \mathrm{ml}$.

$\mathrm{O}$ : untreated strontium carbonate plasma.

+ : preadsorbed strontium carbonate plasma.

A: cobalt carbonate adsorption of untreated and barium phosphate $(80 \mathrm{mg} / \mathrm{ml})$ preadsorbed plasma.

B: barium phosphate adsorption of untreated and cobalt carbonate $(80$ $\mathrm{mg} / \mathrm{ml}$ ) preadsorbed plasma.

C: lead carbonate adsorption of untreated and barium phosphate $(80 \mathrm{mg} / \mathrm{ml})$ preadsorbed plasma.

D: barium phosphate adsorption of untreated and lead carbonate $(40 \mathrm{mg} / \mathrm{ml})$ preadsorbed plasma.
E: cobalt carbonate adsorption of untreated and lead phosphate $(70 \mathrm{mg} / \mathrm{ml})$ preadsorbed plasma.

F: lead phosphate adsorption of untreated and cobalt carbonate $(100 \mathrm{mg} / \mathrm{ml})$ preadsorbed plasma.

G: cobalt carbonate adsorption of untreated and lead carbonate $(40 \mathrm{mg} / \mathrm{ml})$ preadsorbed plasma.

$\mathrm{H}$ : lead carbonate adsorption of untreated and cobalt carbonate $(120 \mathrm{mg} / \mathrm{ml})$ preadsorbed plasma.

adsorption curves are thus the results of matching experiments with compounds adsorbing two different labile factors with synergistic effects.

The activities adsorbed by cobalt carbonate and lead phosphate were due to two different labile factors with independent activities (Figs. 2E and 2F). The activities adsorbed by cobalt carbonate and lead carbonate were also different and unrelated (Figs. $2 \mathrm{G}$ and $2 \mathrm{H}$ ).

The activity adsorbed by lead carbonate was different from and unrelated to the activity adsorbed by lead phosphate (Figs. 3A and 3B), whereas the activities adsorbed by barium phosphate and lead phosphate are due to two different factors with synergistic effects (Figs. 3C and 3D).

The results obtained by the use of these four adsorbents can thus be explained as adsorption of four different labile coagulation factors. For these factors we have adopted the following terms: 

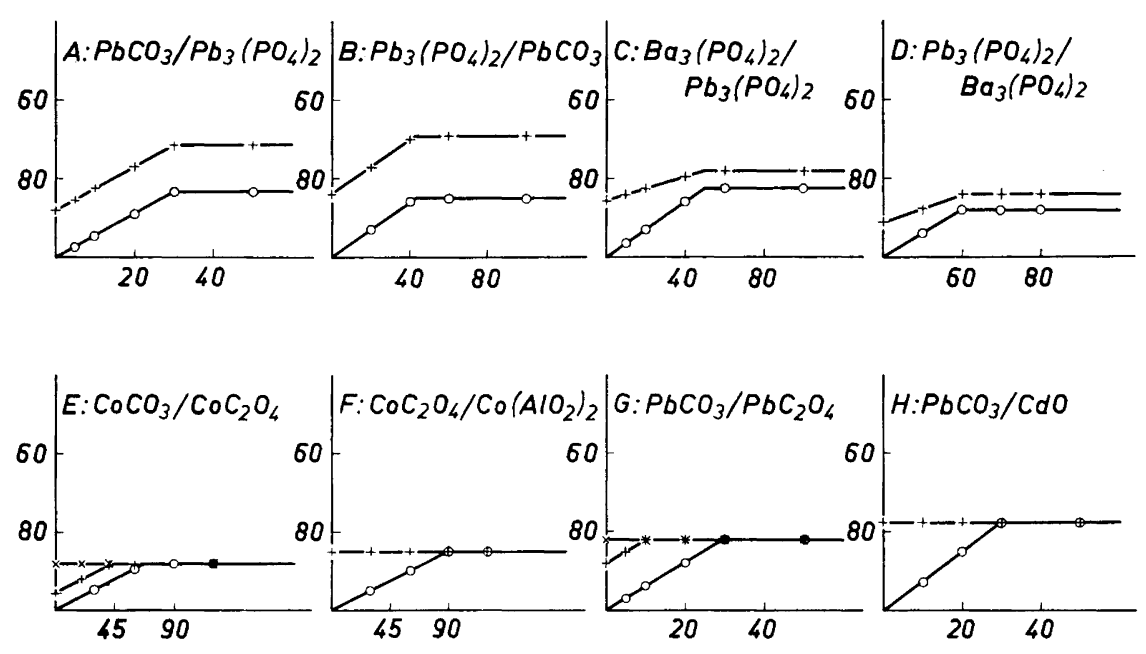

Figs. 3. Comparison of adsorbents II.

Ordinates: labile factor activity in \% of strontium carbonate plasma.

Abscissæ: adsorbent in $\mathrm{mg} / \mathrm{ml}$.

$O$ : untreated strontium carbonate plasma.

+ and $X$ : preadsorbed strontium carbonate plasma.

A: lead carbonate adsorption of untreated and lead phosphate $(60 \mathrm{mg} / \mathrm{ml})$ preadsorbed plasma.

B: lead phosphate adsorption of untreated and lead carbonate $(40 \mathrm{mg} / \mathrm{ml})$ preadsorbed plasma.

C: barium phosphate adsorption of untreated and lead phosphate $(60 \mathrm{mg} / \mathrm{ml})$ preadsorbed plasma.

D: lead phosphate adsorption of untreated and barium phosphate $(60 \mathrm{mg} / \mathrm{ml})$ preadsorbed plasma.

E: cobalt carbonate adsorption of untreated plasma and plasma preadsorbed by $20 \mathrm{mg} / \mathrm{ml}(+)$ and by $60 \mathrm{mg} / \mathrm{ml}(X)$ of cobalt oxalate.

F: cobalt oxalate adsorption of untreated and cobalt aluminate $(40 \mathrm{mg} / \mathrm{ml})$ preadsorbed plasma.

G: lead carbonate adsorption of untreated plasma and plasma preadsorbed by 10 $\mathrm{mg} / \mathrm{ml}(+)$ and by $20 \mathrm{mg} / \mathrm{ml}(\times)$ of lead oxalate.

$\mathrm{H}$ : lead carbonate adsorption of untreated and cadmium oxide $(10 \mathrm{mg} / \mathrm{ml})$ pread. sorbed plasma.

$\lambda$ (lambda)-factor for the labile factor adsorbed by cobalt carbonate, $\pi$ (pi)-factor for the labile factor adsorbed by lead carbonate, $\gamma$ (gamma)-factor for the labile factor adsorbed by barium phosphate, and $\beta$ (beta)-factor for the labile factor adsorbed by lead phosphate.

The effects of $\lambda$-factor, $\pi$-factor and $\beta$-factor are apparently purely additive as are the effects of $\lambda$-factor and $\gamma$-factor. The latter factor, however, appears to act as a synergist both for $\pi$-factor and $\beta$-factor.

The effects of the other adsorbents could by similar experiments be compared to that of each of these four prototypes of adsorbents. 

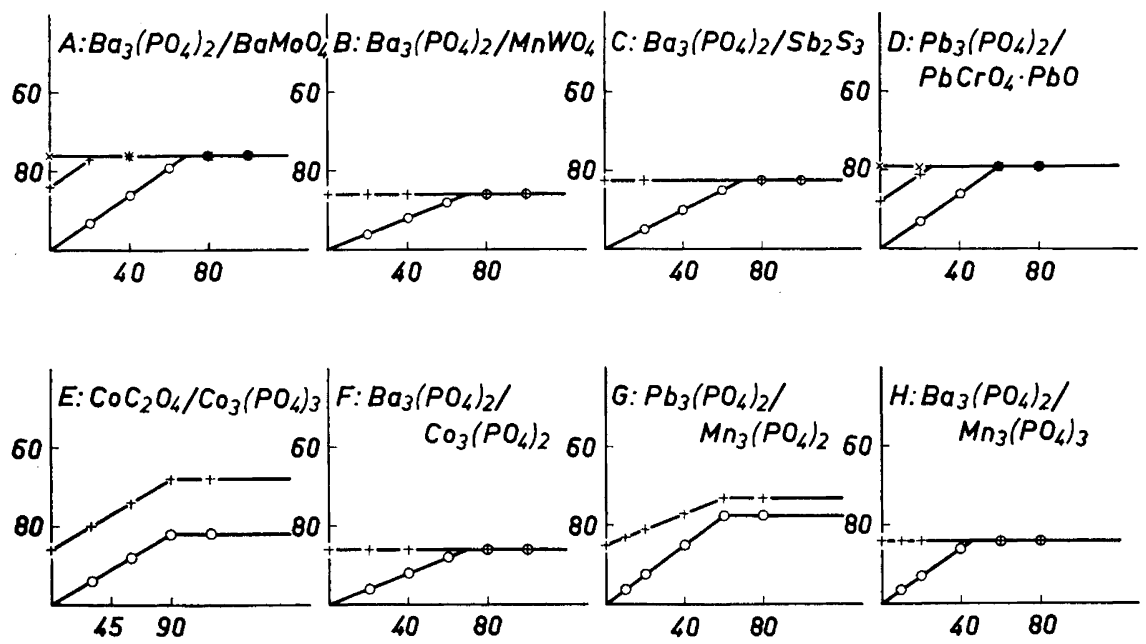

Figs. 4. Comparison of adsorbents III.

Ordinates: labile factor activity in \% of strontium carbonate plasma.

Abscissæ: adsorbent im $\mathrm{mg} / \mathrm{ml}$.

$O:$ untreated strontium carbonate plasma.

+ and $X$ : preadsorbed strontium carbonate plasma.

A: barium phosphate adsorption of un. treated plasma and plasma preadsorbed by $10 \mathrm{mg} / \mathrm{ml}(+)$ and by $20 \mathrm{mg} / \mathrm{ml}$ $(x)$ of barium molybdate.

B: barium phosphate adsorption of untreated and manganese tungstate (40 $\mathrm{mg} / \mathrm{ml}$ ) preadsorbed plasma.

C: barium phosphate adsorption of untreated and antimony trisulfide $(30 \mathrm{mg} /$ $\mathrm{ml}$ ) preadsorbed plasma.

D: lead phosphate adsorption of untreated plasma and plasma preadsorbded by $30 \mathrm{mg} / \mathrm{ml} \mathrm{(+)} \mathrm{and} \mathrm{by} 60 \mathrm{mg} / \mathrm{ml}(\times)$ of basic lead chromate.
E: cobalt oxalate adsorption of untreated and cobalt phosphate $(30 \mathrm{mg} / \mathrm{ml})$ preadsorbed plasma.

F: barium phosphate adsorption of untreated and cobalt phosphate $(30 \mathrm{mg} /$ $\mathrm{ml}$ ) preadsorbed plasma.

G: lead phosphate adsorption of untreated and manganese phosphate $(50 \mathrm{mg} / \mathrm{ml})$ preadsorbed plasma.

$\mathrm{H}$ : barium phosphate adsorption of untreated and manganese phosphate (50 $\mathrm{mg} / \mathrm{ml}$ ) preadsorbed plasma.

Figs. $3 \mathrm{E}$ and $3 \mathrm{~F}$ show that adsorption by cobalt oxalate and cobalt aluminate can reduce the labile factor activity to the same level as obtained with cobalt carbonate and cobalt oxalate, respectively, and that cobalt carbonate and cobalt oxalate cause no further reduction of the activity of plasmas preadsorbed by adequate amounts of cobalt oxalate or cobalt aluminate, respectively. The effects of the latter two adsorbents are thus due to adsorption of $\lambda$-factor.

In the same way it was shown that the effects of lead oxalate or cadmium oxide were due to adsorption of $\pi$-factor (Figs. $3 \mathrm{G}$ and $3 \mathrm{H}$ ). Barium molybdate, manganese tungstate and antimony trisulfide were all shown to adsorb $\gamma$-factor (Figs. $4 \mathrm{~A}-\mathrm{C}$ ). The factor adsorbed by basic lead chromate was identified as $\beta$-factor (Fig. 4D). The factor adsorbed by cobalt phosphate was unrela- 
Fig. 5. Differences in effect between crystalline and amorphous adsorbents.

Ordinate: labile factor activity in $\%$ of strontium carbonate plasma.

Abscissæ: adsorbent im $\mathrm{mg} / \mathrm{ml}$.

O: crystalline barium oxalate, plasma No. 3747.

-: amorphous barium oxalate, plasma No. 3510.

$\square$ : crystalline lead phosphate, plasma No. 313.

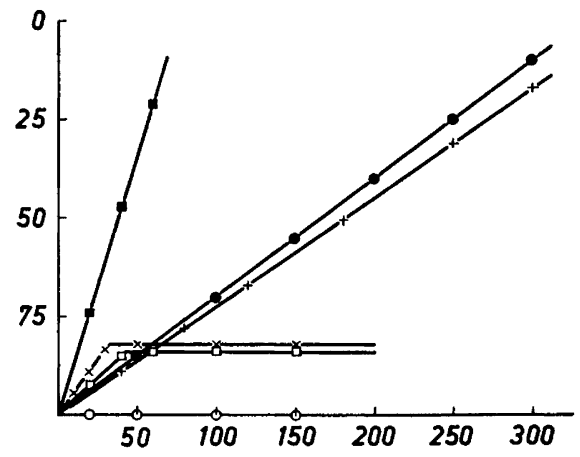

: amorphous lead phosphate, plasma No. 222.

$X$ : crystalline lead molybdate, plasma No. 3565.

+: amorphous lead molybdate, plasma No. 3510.

ted to $\lambda$-factor (Fig. $4 \mathrm{E}$ ) and shown to be $\gamma$-factor (Fig. $4 \mathrm{~F}$ ). Manganese phosphate adsorbed a factor, acting as a synergist for $\beta$-factor (Fig. $4 \mathrm{G}$ ). It was identified as $\gamma$-factor (Fig. $4 \mathrm{H}$ ). By the same technique the effects of all the other adsorbents could be identified as adsorption of $\lambda_{-}^{-}, \pi_{-}^{-}, \gamma_{-}$, or of $\beta$-factor. The results of all these experiments are seen from the last column of Table 1 .

From the recorded experiments it is apparent that the ratio of adsorbable to total activity of strontium carbonate plasmas can vary in different experiments with the same adsorbent or with compounds shown to adsorb the same factor. Such variations, previously observed for the relative activities of $\psi$ and $\sigma$-factors ${ }^{1}$, were ascribed partly to differences in the sensitivity of the substrate plasmas to adsorbable and nonadsorbed factors, and partly to possible differences between individual fresh plasmas in the relative concentrations of these factors. The present discovery of synergistic effects of certain labile factors and purely additive effects of others, shows that the influence of the concentration of non-adsorbed factors on the relative activity of an adsorbable factor is complex. The influence of increased concentrations of factors with additive effects is thus equivalent to decreased concentrations of factors with synergistic effects.

Crystalline versus amorphous adsorbents. It has been stated ${ }^{4}$ that selective adsorption of the $\varkappa_{-}, \delta$ - and $\varphi$-factors was accomplished only by crystalline adsorbents, whereas no clear-cut differentiation of these coagulation activities could be obtained with the corresponding amorphous preparations. For the adsorption of labile factor activity similar phenomena were observed as illustrated by the experiments presented in Fig. 5. The differences in effect of crystalline and amorphous preparations of (1) barium oxalate, of (2) lead phosphate, and of (3) lead molybdate on the labile factor activity of strontium carbonate plasma are quite pronounced. 
Table 2. Labile factors measured by RVV-cephalin or RVV.

\begin{tabular}{|c|c|c|c|c|}
\hline $\begin{array}{l}\text { Treatment of strontium } \\
\text { carbonate plasma }\end{array}$ & \multirow{2}{*}{$\begin{array}{l}\text { Labile } \\
\text { factor } \\
\text { adsorbed }\end{array}$} & \multicolumn{3}{|c|}{$\begin{array}{l}\text { Labile factor activity in } \% \text { of } \\
\text { strontium carbonate plasma }\end{array}$} \\
\hline Adsorbent $\quad \mathrm{mg} / \mathrm{ml}$ & & Tpl. & RVV-ceph. & RVV \\
\hline $\begin{array}{l}\text { Untreated } \\
\text { Lead phosphate }\end{array}$ & $\beta$ & $\begin{array}{c}100^{a} \\
93.5 \\
87 \\
80.5 \\
80.5\end{array}$ & $\begin{array}{c}100^{b} \\
94.5 \\
89 \\
83.5 \\
83.5\end{array}$ & $\begin{array}{l}100 b \\
100 \\
100 \\
100\end{array}$ \\
\hline $\begin{array}{l}\text { Untreated } \\
\text { Cobalt oxalate }\end{array}$ & $\lambda$ & $\begin{array}{l}100^{c} \\
95 \\
90 \\
85 \\
85\end{array}$ & $\begin{array}{l}100^{b} \\
96 \\
92 \\
88 \\
88\end{array}$ & $\begin{array}{c}100^{b} \\
94.5 \\
89 \\
83.5 \\
83.5\end{array}$ \\
\hline $\begin{array}{l}\text { Untreated } \\
\text { Lead carbonate }\end{array}$ & $\pi$ & $\begin{array}{l}100^{d, e} \\
94 \\
88 \\
82 \\
82\end{array}$ & $\begin{array}{l}100^{d} \\
100^{-} \\
\overline{100}\end{array}$ & $\begin{array}{l}100^{e} \\
100 \\
- \\
100\end{array}$ \\
\hline $\begin{array}{l}\text { Untreated } \\
\text { Barium phosphate }\left\{\begin{array}{r}20 \\
40 \\
60 \\
80 \\
100\end{array}\right.\end{array}$ & $\gamma$ & $\begin{array}{l}100^{d, e} \\
95 \\
90 \\
85 \\
82.5 \\
82.5 \\
\end{array}$ & $\begin{array}{l}100^{d} \\
100^{-} \\
\overline{1} \\
100 \\
100\end{array}$ & $\begin{array}{l}100^{e} \\
100 \\
- \\
100 \\
100\end{array}$ \\
\hline
\end{tabular}

$a$ plasma No. 5617; $b$ plasma No. 5045; $c$ plasma No. 5351; $d$ plasma No. 5051; $e$ plasma No. 3445 .

The labile factor activity measured by $R V V *$ cephalin or $R V V$. The effects of the adsorbents were also studied with RVV, with or without added cephalin, replacing thromboplastin in the test system ${ }^{1,3}$. Representative experiments are summarized in Table 2.

Adsorption of $\beta$-factor (by lead phosphate) reduced the labile factor activity measured by RVV-cephalin, but not that measured by RVV alone. Maximal adsorption of the activities measured by thromboplastin and RVV-cephalin was obtained with the same concentration of lead phosphate, viz. $60 \mathrm{mg} / \mathrm{ml}$. Adsorption of $\lambda$-factor (by cobalt oxalate) reduced the labile factor activities measured by all three assay accelerators, and maximal adsorption of activity was obtained with the same concentration of adsorbent, viz. $90 \mathrm{mg} / \mathrm{ml}$. Removal of $\pi$-factor (by lead carbonate) or of $\gamma$-factor (by barium phosphate) had no effect on the labile factor activities measured by RVV-cephalin or RVV. By these experiments $\lambda$-factor was established as a labile factor common to all three coagulation systems. $\beta$-Factor is only active in coagulation systems

* Russell's viper venom, kindly supplied by The Wellcome Research Laboratories, Langley Court, Beckenham, England. 
containing added cephalin, as such or in the form of thromboplastin. The $\pi$ - and $\gamma$-factors must be regarded as thromboplastin specific labile factors.

\section{DISCUSSION}

The present study is part of a systematic investigation on the effects of adsorbents on the labile factor activity of strontium carbonate preadsorbed oxalated chicken plasma. Partial adsorption of the activity by crystalline adsorbents proved its multiple nature and suggested the use of such adsorbents for characterization of the individual components. By matching experiments fifty-two adsorbents tested in this study were found to belong to four different categories of adsorbents, causing adsorption of four different labile coagulation factors. Differences in physico-chemical properties are thus the basis for regarding these factors as different. Differences in the functions of the factors so defined, were indicated by the observed synergistic effects of certain factors and the merely additive effects of others. $\lambda$-Factor is thus functionally different from $\beta$ - and $\pi$-factors because it is not a synergist for $\gamma$-factor, and functionally different from $\gamma$-factor because of its non-synergistic relations to $\pi$ - and $\beta$-factors. $\beta$-Factor and $\pi$-factor differ functionally from $\gamma$ factor by not being synergists for $\pi$-factor or $\beta$-factor, respectively.

Further evidence of the functional non-identity of the factors was obtained in experiments with RVV-cephalin or RVV replacing thromboplastin as assay accelerator. Both $\pi$-factor and $\gamma$-factor were inactive in the RVV-cephalin and RVV assay systems. The activity of $\beta$-factor was found to depend on the presence of added cephalin (or thromboplastin). $\lambda$-Factor was the only factor active in all three assay systems. These observations and the fact that the effect of each adsorbent can be duplicated by at least two others, appear to rule out the possibility that the results can be due to artifacts.

We have not discovered any simple rules as to which factor is adsorbed by what type of adsorbent. $\lambda$-Factor was adsorbed by cobalt compounds only, but cobalt phosphate and cobalt oxide adsorbed $\gamma$-factor, sharing this property with a multitude of apparently unrelated compounds. $\beta$-Factor was adsorbed by a few lead compounds only. All other lead compounds adsorbed $\pi$-factor, duplicating the effects of tungsten and cadmium oxides. The pronounced selective properties of the crystalline adsorbents contrasted sharply with the completely indiscriminate adsorption of labile coagulation factors obtained with amorphous preparations. This is compatible with our previous suggestion ${ }^{1,5}$ that selective adsorption of coagulation factors depends on a rigid spatial pattern of molecules in the surface of the adsorbent which "fits" the structure of a characteristic part of the adsorbable factor, permitting adsorption of one or a few factors only.

It has been pointed out previously ${ }^{1}$ that in a determination of the relative labile factor activities of different plasmas, the same sample of stored plasma and the same solution of accelerator should be employed. The present results indicate that a comparison of the activities adsorbed from two different plasmas by a selected adsorbent, may not permit any conclusions as to the relative concentrations of the adsorbable factor since possible differences in adsorbed

Acta Chem. Scand. 16 (1962) No. 6 
activity may be caused by differences in the concentrations of non-adsorbed synergists. Another possibility for quantitative determination of individual labile coagulation factors is suggested by the observed proportionality between adsorbed activity and amounts of adsorbent. The minimum concentration of adsorbent required for maximal adsorption of labile factor activity may thus be proportional to the concentration of the adsorbable factor, and represent an absolute value for the concentration of the factor. Such values will be independent of the concentration of non-adsorbed factors, but may also reflect possible variations in the concentrations of inert plasma factors if such factors are adsorbed in competition with the labile factor.

\section{REFERENCES}

1. Sørbye, Ø. and Kruse, I. Acta Chem. Scand. 16 (1962) 1221.

2. Sørbye, Ø., Kruse, I. and Dam, H. Acta Chem. Scand. 5 (1951) 487.

3. Sørbye, Ø. and Kruse, I. Acta Chem. Scand. 14 (1960) 2177.

4. Sørbye, Ø. Acta Chem. Scand. 16 (1962) 799.

5. Sørbye, Ø. Acta Chem. Scand. 16 (1962) 903.

Received January 12, 1962. 